\title{
A Correlational Analysis to Assess Major Obstacles Associated with the Internationalization of Saudi Startup Enterprises
}

\author{
Megbel Aleidan ${ }^{1}$ \\ ${ }^{1}$ King Faisal University, School of Business, Saudi Arabia \\ Correspondence: Megbel Aleidan, King Faisal University, School of Business, Saudi Arabia.
}

Received: November 1, 2018

Accepted: November 20, 2018 Online Published: November 27, 2018

doi:10.5539/ibr.v11n12p78

URL: https://doi.org/10.5539/ibr.v11n12p78

\begin{abstract}
Startups' constant tendency to grow and scale up through internationalization is occasionally collided with a number of barriers in the domains of legalization and regulation, market and customer, environment and competitiveness, information and knowledge, resources and accessibility, and economy and culture. The sharpness of these barriers might intensify when it comes to startups from emerging markets. Consequently, a need for assessing the major obstacles associated with the internationalization of emerging markets' startups is emphasized. In this regard, a correlational analysis has been used to identify and assess the role of these obstacles in restricting Saudi startup enterprises to operate internationally. A total of 103 participants were included in the data collection process of the study from Saudi startup enterprises. The findings have shown that liability of foreignness, managerial dispute and organizational distrust, and immaturity of home market were the most influential barrier towards internationalization process of SMEs. Coping implications were suggested to mitigate the impact of each barrier and possible avenues for future research in the area of startups' internationalization were recommended.
\end{abstract}

Keywords: startups, internationalization, obstacles, Saudi Arabia

\section{Introduction}

Startups in emerging countries look forward to grow their businesses as a refreshing occurrence that brings new hope to their regions. Mainly, the startup businesses seek for economic as well as political and social security. In this context, Sinu (2017) has shown the boost got from the startups in India, specifically in growing the economy and empowering youths to spread their talents and innovative ideas in business. In the context of Nigeria, startups have played an important role in achieving and sustaining economic growth by generating innovation, employment, diversifying the economic source of revenue, boosting the small and medium enterprises (SMEs), and increasing production (Ogunlana, 2018). In the context of Germany, startups boost economic growth of the country by instigating products, services and innovative technologies. Similarly, new job opportunities are provided by startups in the short and long term, accelerating structural changes by replacing sclerotic companies, increasing competition, and raising the productivity of economies and firms (Kritikos, 2014). Undertaking the paradigm of Romania, Herte (2017) emphasizes the role of startups in boosting economic growth of the country by creating job opportunities, ensuring social stability, encouraging innovation and entrepreneurship, boosting employment and competitiveness, improving the business environment, and generating opportunities to access funds through different programs.

According to OECD (2005), the share of SMEs in international markets is inappropriately low towards the role they play in their national economies as these startups comprise the most important economic growth and employments source all over the world. One of the major reasons of this low proportion is barriers of internal and external character, restricting or precluding the expansion of SMEs on foreign markets (Pietrasieński \& Ślusarczyk, 2015). Correspondingly, Roy, Sekhar \& Vyas (2016) have emphasized informational barriers, financial barriers, marketing barriers and managerial barriers as internal barriers whereas governmental and economic barriers, task and socio-cultural barriers, procedural and currency barriers, and political/legal barriers as external barriers. Likewise, Toulova, Votoupalova \& Kubickova (2015) have listed lack of experience and language barriers as internal barriers, while lack of finance was revealed as the most important external barrier among Czech SMEs. In the context of India, Kalyanasundaram (2018) has revealed delays in product delivery, government policies, lack of finance, and lack of market knowledge as major causes of failure to startups 
internationalization. Similarly, these startups lack time to realize product development, revenue realization, market growth, government policy leverage and personal characteristics, which causes into the failure of internationalizing their activities. In the context of Lithuanian startups, Sekliuckiene (2013) company's size, lack of knowledge, lack of financial resources, inability to contact to distributors and customers, lack of experience, company's scale as internal barriers for internationalization. On the contrary, bureaucratic problems and processes, intensive competition, verbal and nonverbal language differences, geographical distance, problematic communication with overseas customers, cultural differences in particular areas, national and target market regulations, and licenses and approvals on activities are revealed as external barriers for internationalization. Severe financial conditions and labor market constraints are considered as major external barriers for internationalization among German startups (Arndt, Buch \& Mattes, 2009). Likewise, tariff and non-tariff barriers, exchange rates, limited resources and funds, and foreign government customs and restrictions are revealed as barriers for internationalization (Patmore \& Haddoud, 2015).

For Saudi Arabia (the country in which this study took place), different practices were witnessed as compared to the Western context, resulting in limited contribution of Saudi SMEs to national GDP (Azyabi, 2013). According to Babagi (2017), the contribution of Saudi SMEs can be proportionally higher if they overcome their encountered challenges. Alharbi (2014) has revealed lack of financial, institutional, marketing, development, educational, and legal services support as obstacles to the success and growth of Saudi startups.

\subsection{Contribution of the Study}

From an internationalization perspective, no previous and existing studies managed to provide empirical evidences on the internationalization of Saudi startups and its associated barriers. Meaning that the current study is considered to be first to empirically investigate the obstacles or barriers to internationalization for Saudi Arabia startups. Therefore, this study is required to provide Saudi startups' decision makers with explanations and implications on the potential role played by obstacles in restricting the stimulation of their companies' internationalization and ways to cope with them.

\section{Literature Review and Hypotheses Development}

International penetration for small and medium startup companies has been enabled through globalization to offer long-term competitive advantage. However, such penetration of foreign markets is usually hindered by a series of obstacles, which ultimately prevents these startups from internationalizing their activities.

\subsection{Lack of Owners' International Experience}

The lack of owners' experience towards internationalization activities is an utterly negligible subject towards the success of startups. Correspondingly, the owners who operate their businesses without having an exposure to international experience and knowledge are likely to not successfully internationalize the activities of their startup firms (Chachar, 2013). Chelliah et al (2010) revealed that lack of international experience of firms' owners is the major weakness towards the internationalization activities of their firms. Likewise, Wang et al (2007) have stated that lack of international experience and knowledge of owners is detrimental to strategic execution and internationalizing activities in small and medium businesses. Similarly, Hutchinson et al (2009) have stated that lack of experience and knowledge of startups' owners hinders internationalization and usually prevents them to convey the distinctive qualities and image of a product or a service to consumers overseas. The following hypothesis is developed to validate the lock of owners' international experience on the internationalization of their startups;

\section{H1: Lack of owners' international experience prevents the internationalization of their startups' activities.}

\subsection{Lack of Funds}

Finance is observed as important part of the development ability of startups and it is stated as a holding element of an enterprise. Funds allow enterprise to grow and nurture the needs to invest in different areas; for instance, increased capacity, updated technology and market development. However, lack of funding is considered as another important barrier towards the internationalization of startups and; therefore, these entities are not able to develop their ability to sustain in a well-established market (Eriksson, 2017). Abdin (2016), argued that startups are often low investment firms as they do not have accessible and available funds to operate trade of their own cost. Due to limited access to institutional funds, these entities lack to utilize financial when they penetrate foreign markets. According to the report of OECD (2017), access to funds in the suitable and proportionate forms is hindered by a range of demand and supply obstacles for several startups. For instance, credit constraints, and lack of collateral and fixed costs are major obstacles of financing. Correspondingly, Fuentes (2017) has reported that $67 \%$ of SMEs in the form of startups failed to internationalize their activities due to lack of funding 
or financial resources. Based on the aforementioned discussion, this study has proposed following hypothesis;

\section{H2: Lack of funds affects the internationalization of startups.}

\subsection{Immaturity of Home Market}

Entrepreneurs need to switch their operations out of their home market for internationalization to take place. It has been emphasized that a firm possess its ownership advantages and constitutes its own character from its home market. This implies that a startup as a learning organization is required to initiate its processes in a home market that is characterized by its maturity and its ability to foster the disruptive and innovative dynamic capabilities of its newly established ventures. According to Anna and Ida (2017), the immaturity of home market can hamper or decelerate the internationalization of startups. Correspondingly, Karlsson and Rydqvist (2017) have revealed that the immaturity of the startups' home markets may encourage them to move towards similar immature markets and adapt their internationalization activities accordingly, which ultimately might negatively affect their strategic expansion plans in their industry. The immaturity of the startup sector in a specific home market, with limited possibilities of spillover and exchange of advanced and sophisticated knowledge among the startups might lead them to ignore market-seeking opportunities outside of their home market. This can be converted into the following hypothesis;

\section{H3: Immaturity of home market negatively affects the internationalization of startups.}

\subsection{Depth and Size of Home Market}

The choice of startups to internationalize in foreign markets is based on the situational motivators such as size, dimension, and excess capacity, depth of market, unsolicited orders and common market membership. Likewise, capabilities of startups such as their size and scale are developed with a long-lasting perspective. This makes it vital for startups to screen its home market first and develop their capabilities through exploiting the untapped niches within it prior to committing their future overseas (Kozlova, 2014; Stouraitis \& Kyritsis, 2016). As a consequence, startups in large and deep home markets may tend to spend a relatively long time domestically before internationalizing their activities in comparison with their counterparts in small home markets for demand purposes. Operating domestically for a sufficient period of time can enhance the capacity of the startup to acquire the size and maturity required for internationalization since the small age and size of the firm are amongst the major uncertainties and barriers that prevent and cause a possible failure (Yener, Doğruoğlu \& Ergun, 2014; Baranovskaja, 2015; Kozlova, 2014; Stouraitis \& Kyritsis, 2016). The following hypothesis is developed to detect the impact of the depth and the size of the home market on internationalization;

H4: The extended depth and the large size of home market negatively affect the internationalization of its startups.

\subsection{Weak Absorptive Capability}

It has been indicated that early startups can rapidly learn and grow in international markets as compared to older entrants, but they might probably lack international knowledge or merely have narrow skill foundation. For instance, new internationalizers have limited learning about markets and competition as compared to their established competitors. It has been argued that early internationalizers have limited operational experience if they internationalize at an early age. Thereby, startups require a suitable level of absorptive capacity to comprehensively benefit from the learning advantage of internationalization. Early internationalization cannot bring performance advantages as internationalization exposes a firm to uncertainties and risks (Castro Abancens \& Cepeda-Carrión, 2016; Saeedi, 2014; Aljanabi, Noor \& Kumar, 2014; Onwuzuligbo \& Hurmelinna-Laukkanen, 2017; Wu \& Voss, 2015). Startups with firm absorptive capacity can incorporate and access novel ideas and approaches as well as can robustly position themselves in the host country. Therefore, we propose the following hypothesis;

\section{H5: Weak absorptive capacity can hamper or prevent internationalization of startups.}

\subsection{Managerial Dispute and Organizational Distrust}

The internationalization decision is commonly based on the perceptions about the external and environment actors as compared to organization-related perceptions. Due to diverse and probably negative perceptions concerning internationalization and choice of the foreign market, startups' owners and management personnel might enter into a dispute that is characterized by mutual distrust. Decisions pertaining to internationalization, choice of host country and mode of entry are entirely based on perceptions about managerial preferences. This is resulted in differences in perceptions on other aspects of the internationalization like assessment of external opportunities, partners of performance, growth pressures, and fulfillment of the changing needs in the foreign 
markets. All these factors ultimately lead to the occurrence of managerial dispute and organizational distrust towards internationalization (Ruigrok \& Wagner, 2003; Mupemhi, Duve \& Mupemhi, 2013; Amann, 2003; Agndal, 2004; Sieler, 2008). Therefore, the following hypothesis is worth of validation;

\section{H6: Managerial dispute and organizational distrust directly affects the internationalization decision of startups.}

\subsection{Liability of Foreignness}

Many studies have shed light on the phenomenon of internationalization and its inevitable consequences. Competing in a foreign market makes it imperative for firms, notably, startups to encounter the hazard of the liability of foreignness (LOF) and its associated risks (Zhou \& Guillen, 2016). As an outcome of the severe effect of these risks, many startups tend to intentionally neglect the option of going international, especially if they are uncertain about their ability to overcome the liability of foreignness (Kaiser \& Sofka, 2006). Firm based LOF, on the other hand, derives from firm-specific characteristics including ownership structure, firm-specific resources, learning, and network based linkages such as affiliation to a business group (Johanson and Vahlne, 2009; Petersen and Pedersen, 2002). Stated differently, the magnitude of LOF that different firms face in a given market will vary based on certain firm specific characteristics. Furthermore, we argue that both the environmentally-derived and firm based LOF are different for emerging We following hypothesis;

\section{H7: Liability of foreignness discourages startups to internationalize their activities.}

\subsection{Relocation of Employees Overseas}

For startups, human resources are the backbone of the organization and the drive behind the successes of the business. Therefore, startups with the desire to internationalize usually tend to relocate their key employees to the target foreign market (Vineburgh, 2010). This tendency is relied on two facts, represented in the limited staff startups usually have, especially at their early stages and the strategic importance of the first generation of their employees given into account their contribution to the initiation of the business (Wu \& Voss, 2015). This makes startups forced to relocate some of those key employees to the overseas market to ensure a successful launch of their business there. However, the decision of relocation staff overseas might be collided with intense resistance by the selected staff for personal reasons and preferences and it can entail a number of unaffordable costs (Stouraitis \& Kyritsis, 2016). This eventually may lead the startups to reconsider their decision and postpone the internationalization process to a later stage of their life. This decision can be validated using the following hypothesis;

H8: Relocation of employees overseas can postpone the internationalization of startups.

\section{Methodology}

A quantitative study was conducted through the use of structured questionnaires. The questionnaire survey used in this study was designed for owners and CEOs of startup enterprises. The startup enterprises that had 249 employees or less were chosen for the study. The questionnaires were distributed to start-up enterprises in the cities of Riyadh Region and Eastern Region of Saudi Arabia. The survey was conducted on 170 respondents; however, responses were received from 103 owners and/or CEOs of startups. The questionnaire was designed in English but was translated into Arabic by certified translation services for clarification purposes. To maintain a high degree of accuracy, the translation process was checked by the professionals at the King Faisal University Translation Center.

The content of the questionnaire was developed according to the barriers that prevent/hamper/postpone the startup enterprises from going international and investing overseas. The questionnaire was divided into two parts; the first part is designed to collect information about the company size, sector and years of experience. The second part comprises of questions that investigate the major barriers faced by the startup enterprises in the process of internationalization. These barriers include lack of owners' international experience, lack of funds, immaturity of home market, depth and size of home market, weak absorptive capability, managerial dispute and organizational distrust, liability of foreignness, overseas relocation of employees. The data gathered through the questionnaires was analyzed statistically using Statistical Package of Social Sciences (SPSS) version 20.0. Descriptive and inferential statistics have been used to analyze the collected data.

\section{Results}

The results are presented on the basis of startup enterprises' responses toward barriers, and obstacles associated to internationalization. The profile of these enterprises is presented in Table 1. As per the findings, $57.1 \%$ startup enterprises were micro-size enterprises who employ 0-9 employees, $25.3 \%$ startup enterprises were small enterprises who employ 10-49 employees while 17.6\% companies were medium enterprises, employed 50-249 
people. Mostly startups have 4-5 years of experience (46.4\%) while $40 \%$ startup firms have 0-3 years of experience. A total of $47.1 \%$ startups belong to information and communication services sector, $30.6 \%$ startups belong to logistic services sector, $15.9 \%$ startups belong to retailing sector, and $6.5 \%$ startups belong to wholesaling sector.

Table 1. Enterprises Profile

\begin{tabular}{|c|c|c|c|}
\hline & & $\mathrm{N}$ & $\%$ \\
\hline \multicolumn{4}{|l|}{ Company size } \\
\hline & $0-9$ & 59 & 57.1 \\
\hline & $10-49$ & 26 & 25.3 \\
\hline & $50-249$ & 18 & 17.6 \\
\hline \multicolumn{4}{|c|}{ Years of Experience } \\
\hline & $0-3$ years & 41 & 40 \\
\hline & $4-5$ years & 47 & 46.4 \\
\hline & $6+$ & 15 & 13.5 \\
\hline \multicolumn{4}{|l|}{ Sector } \\
\hline & Logistic services sector & 31 & 30.6 \\
\hline & Retailing sector & 21 & 15.9 \\
\hline & $\begin{array}{lr}\text { Information } & \text { and } \\
\text { communication } & \text { services } \\
\text { sector } & \end{array}$ & 48 & 47.1 \\
\hline & Wholesaling sector & 3 & 6.5 \\
\hline
\end{tabular}

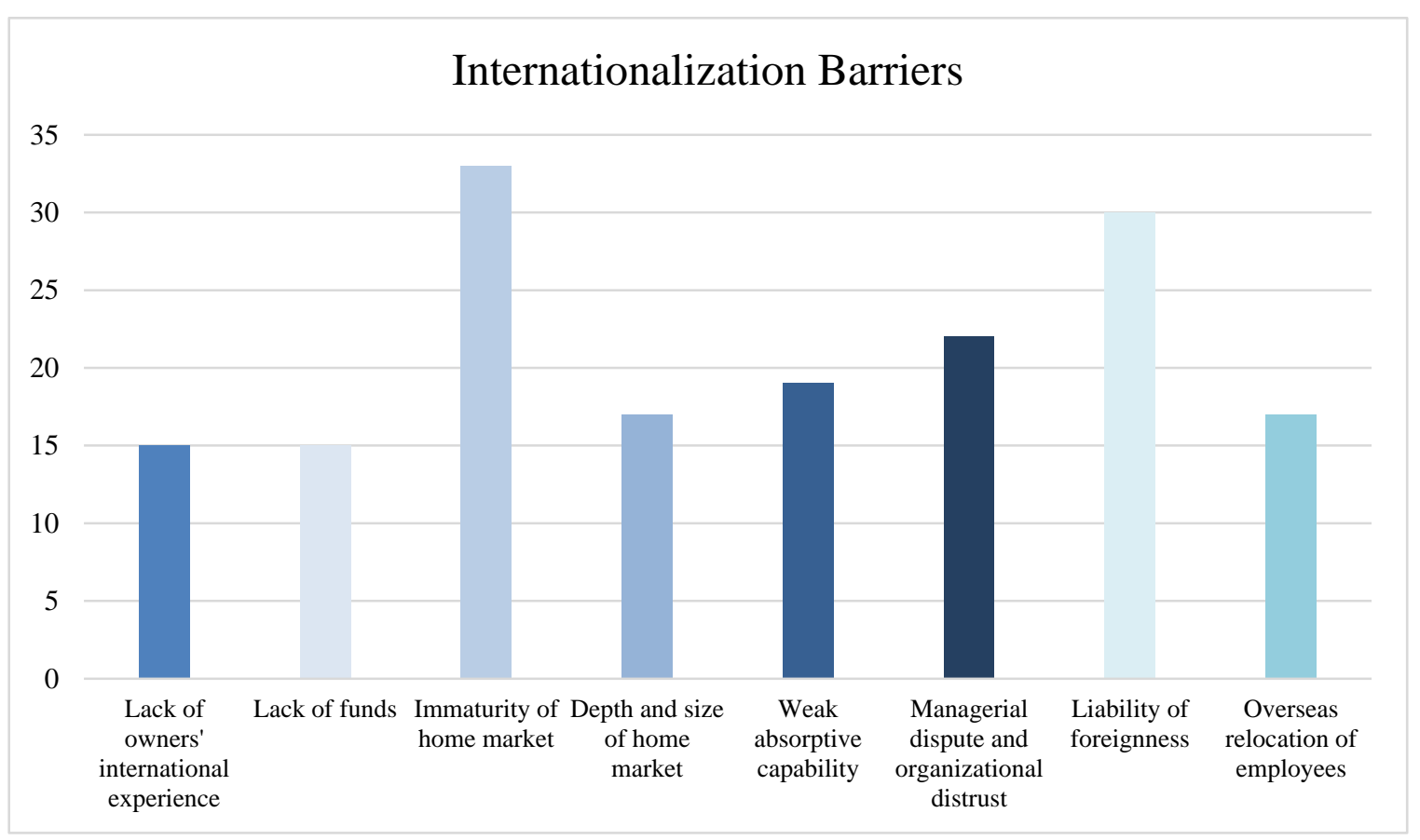

Figure 1. Internationalization Obstacles

Figure 1 shows the obstacles faced by Saudi startup enterprises toward internationalization. As per the findings, immaturity of home market was rated as the most affective barrier faced by Saudi startup enterprises toward internationalization followed by liability of foreignness, managerial dispute and organizational distrust, weak absorptive capability, depth and size of home market, and overseas relocation of employees. 
Table 2. Startup Enterprises towards Internationalization Barriers

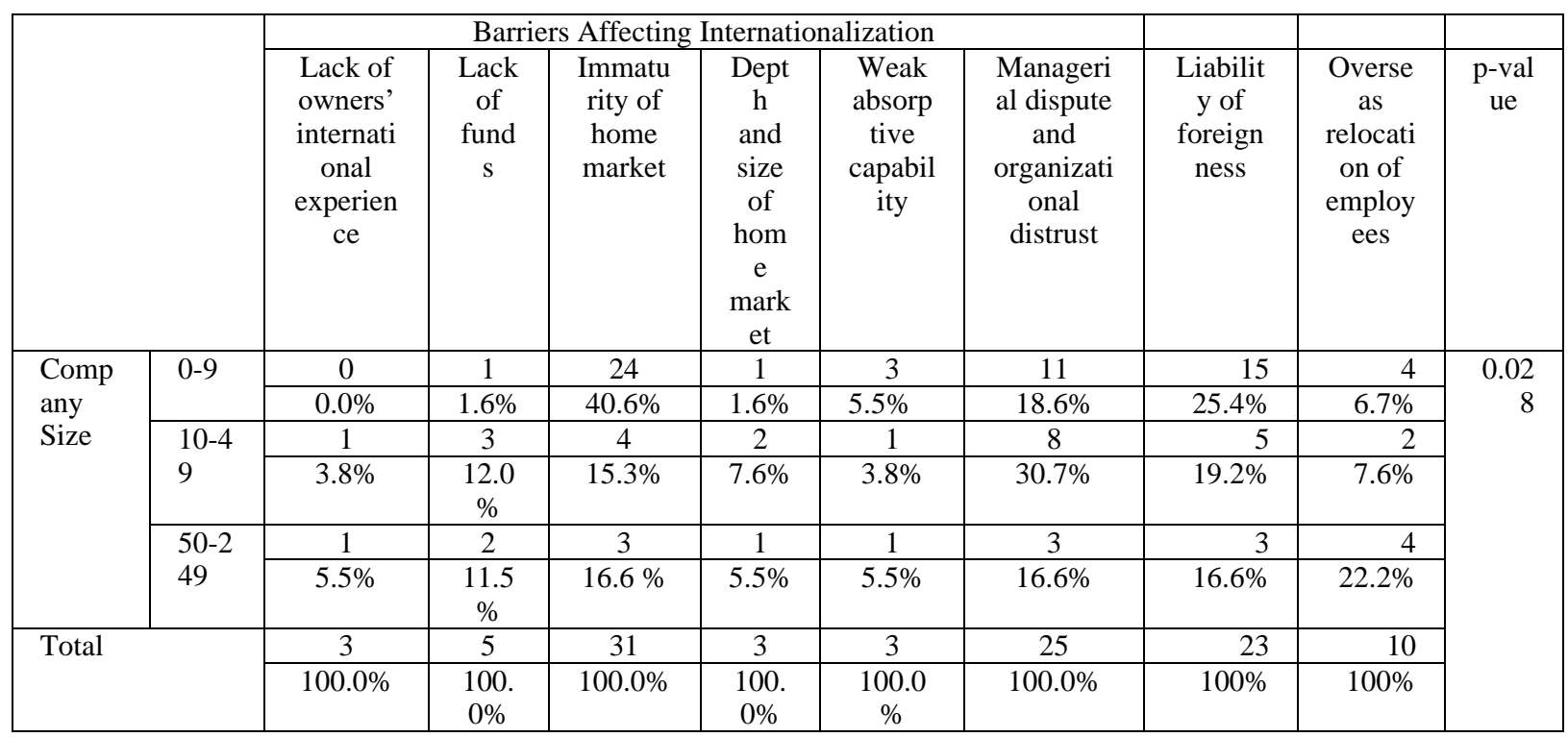

Table 2 has presented the perception of startup enterprises towards internationalization barriers. The findings have shown that immaturity home market was the most influential barrier towards internationalization process of micro enterprises followed by managerial dispute and organizational distrust, and liability of foreignness. Similarly, managerial dispute and organizational distrust, liability of foreignness, and immaturity of home market were the most influential barriers affecting the internationalization process of small enterprises. In contrast, overseas relocation of employees, managerial dispute and organizational distrust, liability of foreignness, and immaturity of home market were the influential barriers affecting the internationalization process of medium enterprises. Furthermore, the results of chi-square statistics showed a significant and positive affect of internationalization barriers on the internationalization process of Saudi startup enterprises.

Table 3. Company's perception towards Internationalization Obstacles

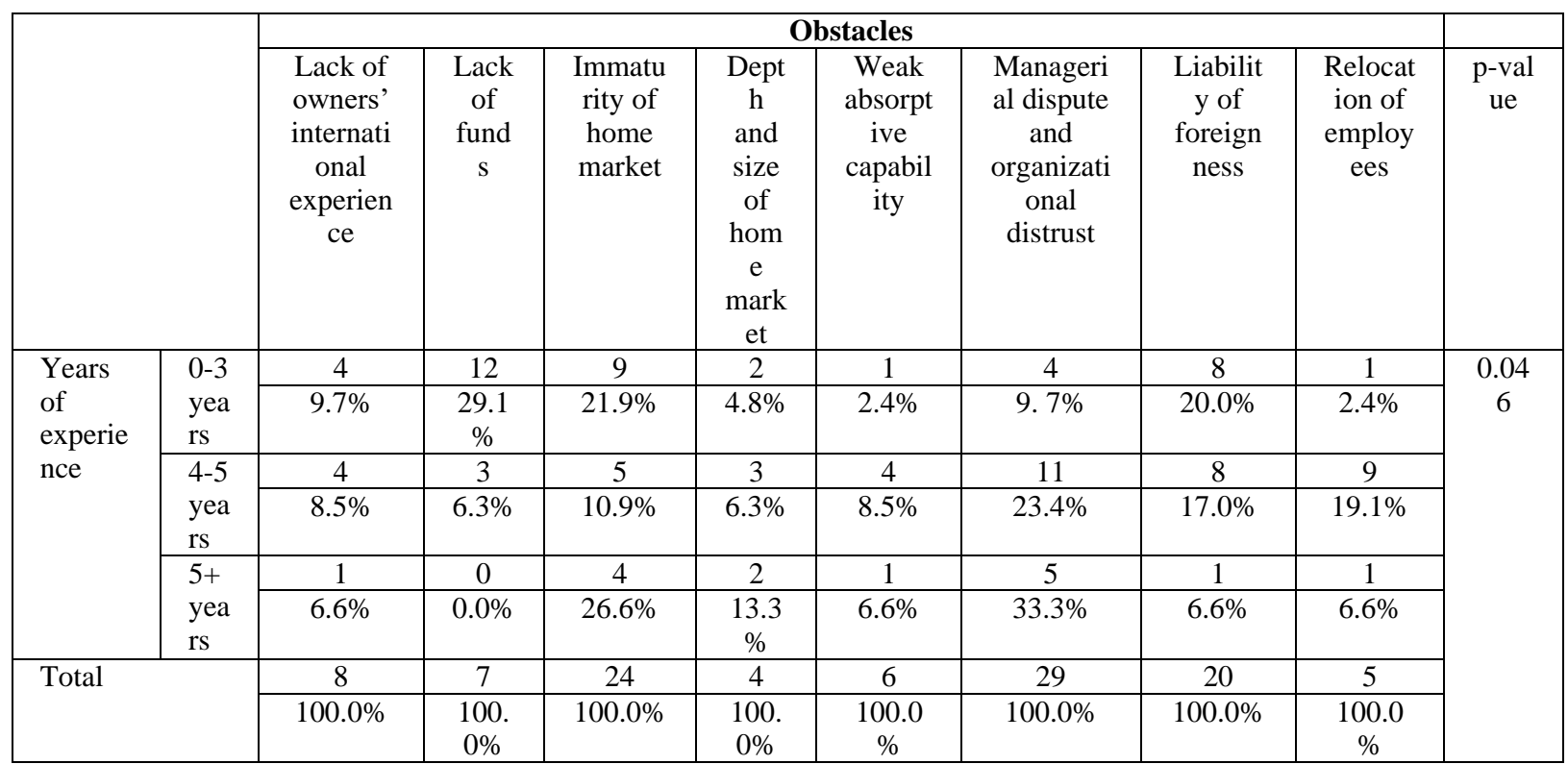

Table 3 presents the company's perception towards obstacles associated to internationalization. As per the findings, lack of funds, immaturity of home market, and liability of foreignness were the most common barriers affecting the internationalization process of enterprises with 0-3 years of experience. In the same vein, managerial dispute and organizational distrust, relocation of employees and liability of foreignness were the barriers to internationalization for enterprises with 4-5 years of experience. In contrast, managerial dispute and organizational distrust, immaturity of home market, and depth and size of home market were the barriers to internationalization for enterprises with $5+$ years of experience. 


\section{Discussion}

\subsection{Lack of Owners' International Experience}

The skills, experience and operating behavior of private business owners that were successful under communism were not compatible with the free market environment after the transition, negatively affecting their ability to compete with foreign investors as well as with new start-ups.

The concept of "the learning advantage of newness" within organizational learning theory (Autio et al., 2000) might also be useful in explaining the internationalization patterns of entrepreneurial start-ups during periods of transition. This concept suggests that newly established firms demonstrate greater flexibility than older ones, allowing them, in this case, to assimilate knowledge on international markets more efficiently. However, even this theory may not outweigh all the impediments of internationalization that result from an unstable institutional environment and the absence of specialized knowledge and skills, particularly during the initial phases of transition.

Although this barrier does not entail a great significance when it comes to startups' internationalization according to the results of the current study and in opposition to what Kubickova et al (2014) found, startups still need to consider to develop international experiences of their decision makers prior to their potential internationalization. A possible way to develop these experiences without a direct engagement in the international market is through developing "arm-length relationships" with actors in that market via contractual agreements.

\subsection{Lack of Funds}

Lack of funds is emerged as an influential barrier affecting the internationalization of Saudi startups. However, this study fails to show that Saudi startups fail to internationalize their activities due to lack of funds. This indicates that entrepreneurs are likely to rely on external financing when there is a lack of in-house resources (Mann \& Sanyal, 2010). Therefore, it is important for startups to acquire make sure that they have different financing options in their target foreign markets increase their chances of having a successful and sustainable international experience. Secondly, venture capital might be one of these options when it comes to maximizing the return of startups' investment in the foreign market. Lastly, the management and decision-making process of the startups can be also affected from the accumulation of fund from friends and family sources.

\subsection{Immaturity of Home Market}

The findings have shown a higher extent of influence of immaturity of home market as a barrier to internationalization in Saudi Arabia. This finding has been supported by previous studies and reported that the entrepreneurial ecosystem is the main factor affecting the internationalization of small and medium enterprises (SMEs) (Toulova, Votoupalova \& Kubickova, 2015; Stouraitis \& Kyritsis, 2016; Pietrasieński \& Ślusarczyk, 2015). Similarly, constraints and voids in firms afflict the emerging markets, which also lead to immature home markets (Prashantham \& Yip, 2017). The consequence of such barrier will be resulted in the form of poor access to reliable information, unsound governance, and weak property rights. Thereby, competition is lacking in fair play and can be potentially dysfunctional. The development of trusting relationships and institutions will be weakened through unreliable and unnecessary enforcement activities (Andens\& Pendegraft, 2016). Multinational startups identify high-quality startups due to the lack of robust entrepreneurial ecosystem rather than their counterparts in mature markets. The resources or legitimacy lack among emerging economies to seek access to multinational corporations. Therefore, following propositions have been made to overcome the influence of this barrier. Firstly, the ecosystem, financing, and culture should be included as a three-fold pillar to create an environment for boosting innovation, employment, and growth in startup activities. Secondly, an entrepreneurial culture and financing should be promoted from inception to critical size with a proactive promotion of entrepreneurship and mindset. Mentoring program for startups can be a win-win strategy to train employees according to the culture and activities of international markets.

\subsection{Depth and Size of Home Market}

Depth and size of home market are not an important barrier when it comes to the internationalization process as elucidated from the findings. It is important for startup firms to prefer the home market with great depth and large size to accomplish the domestic demand rather than going international. This explains the hesitation of some startups to penetrate the international market within their five years of initiation. However, startups should capitalize on the sophisticated sorts of knowledge and know-how existing in some foreign markets and harness them for the interest of their domestic operations. Therefore, the option of going international should not be overlooked even in the cases of high domestic demand. 


\subsection{Weak Absorptive Capability}

The influence of absorptive capability on the internationalization phase of startups in Saudi Arabia is found to be at a minimal extent. According to Techatassanasoontorn et al (2010), unpredictable changes or unforeseen conditions present within and outside the firms weaken the absorptive capability in dynamic environment. Therefore, the presence of internal and external factors should be triggered to seek the need of learning and integrate new knowledge while internationalizing. Managers should engage themselves in alternative activities that can lessen down the extent of events, which include modifications in technology and innovations, regulations, and poor performance. The potential absorptive capability of the startups can be increased if they invest in their research and development department. By recognizing business opportunities in the absorptive capacity of startups, the decision to enter in the international market of owners can be influenced positively. When integrating new practices, a shift in the perceptions of managers and employees is required that can influence the startups' culture (Onwuzuligbo \& Hurmelinna-Laukkanen, 2017).

\subsection{Managerial Dispute and Organizational Distrust}

The findings of the study have shown that managerial dispute and organizational distrust is another barrier that impede the internationalization process in Saudi Arabia. In this regard, Vineburgh (2010) has asserted that the values, principles, processes, and systems involved in the internationalization phase are disrupted due to managerial dispute and organizational distrust. Therefore, several implications have been proposed to overcome the influence of this barrier specifically in the internationalization phase. Firstly, faculty socialization should be emphasized by owners or leaders to assist employees at managerial level for understanding and internationalizing principles, systems, processes, and values of their firms on a comprehensive level. Secondly, alternative means should be developed by leaders for advancing professional development in spite of the resource constraints that are specifically evident in startup firms. Collaboration between managers and owners at every aspect of the internationalization phase must be a do-able objective to assure the continuation of professional development, even under fiscal exigency.

\subsection{Liability of Foreignness}

The findings have indicated that liability of foreignness is amongst the most influential barrier to internationalization after immaturity of home market, and managerial dispute and organizational distrust in Saudi Arabia. This finding has been supported from the findings of Gaur, Kumar \& Sarathy (2011) who asserted that the liability of foreignness can be alleviated by managers of internationalizing firms through capitalizing firm-specific and environmental conditions. Therefore, few implications are proposed to support these findings. Firstly, internationalizing firms can focus on particular industry conditions, organizational structure, and internationalization motives with the higher perceived liability of foreignness rather than differences in institutional development when planning to enter in the internationalization phase. Secondly, the environmental factors can be focused such as diversity in cultures and institutions to result in higher liability of foreignness while entering from a position of strength.

\subsection{Relocation of Employees Overseas}

The findings have shown that relocation of employees overseas was an influential barrier to internationalization but at minimal extent. However, it has been validated that foreign-born employees having knowledge, preferences, price sensitivity, and willingness to trends about their countries of birth can be a potential resource for firms in the internationalization phase (Gould, 1994; Rauch, 1999). The reason behind positive deployment is that the internationalization efforts might be complicated due to flawed, distorted or even false information, and; consequently, augment the internationalization cost. Therefore, one implication to overcome this barrier is to recruit employees from the host countries who share comparable mindsets to their counterparts in the startup's home country. It can be also suggested that, startups might rotate key staff between home and host markets to ensure rigid establishment of their organizational culture in the foreign markets. Furthermore, startups can provide potential deployed employees from the home market with the necessary cultural, organizational and financial support to alleviate or mitigate uncertainties faced by them during the internationalization journey (Hatzigeorgiou \& Lodefalk, 2017).

\subsection{Strengths and Weaknesses}

The aforementioned findings have presented several strengths of the paper that will add significant insight for future studies and startup enterprises. Firstly, this study is the first to explore the major obstacles associated with the internationalization of Saudi startup enterprises in Saudi Arabia. Previously, these obstacles have not been clearly explored whereas opportunities were extensively presented. Secondly, this study has significantly 
presented insights and justifications to the obstacles identified in its context. Thirdly, this study has provided a competitive advantage for startups' decision-makers to identify and overcome the barriers associated with internationalization. It will also assist them in identifying the severity of obstacles affecting their eventual success or failure in the internationalization process. In contrast, the study has only explored and assessed obstacles associated to internationalization; thereby, opportunities for startup enterprises following to internationalization have not been assessed in parallel.

Methodically, future studies should include more companies to present better representation of the population. Secondly, they should also increase the share of medium-sized startups in the aggregate number of the sampling companies. They might also explore the use of post-hoc analysis to indicate the obstacles that mostly influence the internationalization of startup enterprises. Theoretically, future researchers might find it interesting to explore startups' expectations from their home countries' governments when it comes to internationalization as a possible avenue for upcoming studies.

\section{Conclusion}

The study investigated the barriers to internationalization for Saudi startup enterprises and reported immaturity of home market, liability of foreignness, managerial dispute and organization distrust were the most influential barriers affecting the internationalization process of Saudi startup enterprises. The business activities of startups will be strengthened and their possibility to perform better as compared to internationalized firms with suitable absorptive capacity at home and internationally in addition to having a well-established organizational culture that can support openness to foreign markets. Several implications have been suggested to cope with each barrier, which allow startups to lessen down the extent of barrier to the internationalization phase. Despite identifying findings related to the barriers to internationalization, some limitations have been found in this study. Firstly, the study has only included few sampling firms from the category of medium-sized startups. Secondly, the study was unable to include startups from other regions of the country besides the ones from the Eastern Region and the Riyadh Region due to accessibility reasons.

\section{References}

Abdin, M. (2016). Challenges to Internationalize Bangladeshi SMEs.

Agndal, H. (2004). Internationalisation as a process of strategy and change: a study of 16 Swedish industrial SMEs (Doctoral dissertation, Internationella Handelshögskolan).

Alharbi, M. M. (2014). Barriers to franchising in Saudi Arabia. Journal of Marketing Channels, 21(3), 196-209. https://doi.org/10.1080/1046669X.2014.913218

Aljanabi, A. Q. R. A., Noor, N. A. M., \& Kumar, D. M. (2014). The mediating role of absorptive capacity in its effect on organizational support factors and technological innovation. Information Management and Business Review, 6(1), 25.

Amann, W. (2003). The impact of internationalization on organizational culture: A comparative study of international US and German companies (Doctoral dissertation, Verlag nicht ermittelbar).

Anna, B., \& Ida, S. (2017). Factors Important for Rapid Internationalization: A Multiple Case-Study of Born Global Internet-Based Service Firms in Sweden.

Arndt, C., Buch, C. M., \& Mattes, A. (2009). Barriers to internationalization: Firm-level evidence from Germany (No. 52). IAW-Diskussionspapiere.

Azyabi, N. (2013). Knowledge Management Strategic Orientation is SMEs. Monash University, PhD thesis.

Babagi, M. S. (2017). The Internationalization Processes in Saudi Arabia: The Relationship between International Entry Mode and Business Growth in SMEs. Proceedings of 134th the IIER International Conference, Dubai, UAE.

Baranovskaja, K. (2015). Finnish SME's internationalization analysis. Entry modes to Russian market: Case study of Tonester Oy Ltd.

Castro Abancens, I., \& Cepeda-Carrión, G. (2016). Social capital, absorptive capacity and entrepreneurial behaviour in an international context. European Journal of International Management, 10(4), 479-495. https://doi.org/10.1504/EJIM.2016.077426

Eriksson, A. (2017). Government Financing of SMEs: A case study of the Swedish business development check for internationalization.

Fuentes, D. D. (2017). The internationalization of SME in Cantabria. SME Internationalisation Exchange' 
Project.

Gaur, A. S., Kumar, V., \& Sarathy, R. (2011). Liability of foreignness and internationalisation of emerging market firms. In Dynamics of Globalization: Location-Specific Advantages or Liabilities of Foreignness? (pp. 211-233). Emerald Group Publishing Limited. https://doi.org/10.1108/S1571-5027(2011)0000024016

Gould, D. (1994). Immigrant Links to the Home Country: Empirical Implications for US Bilateral Trade Flows. Review of Economics and Statistics 76(2), 302-316. https://doi.org/10.2307/2109884

Hatzigeorgiou, A., \& Lodefalk, M. (2017). Anti-Migration as a Threat to Internationalization? (No. 302). The Ratio Institute.

Herte, A. D. (2017). SMEs and Start-Ups. Importance and Support Policies in European Union and Romania.

Hutchinson, K., Barry, Q., Nicholas, A., \& Doherty, A.M. (2009). Retailer internationalization: overcoming barriers to expansion. The International Review of Retail, Distribution and Consumer Research, 19(3), 251-272. https://doi.org/10.1080/09593960903233673

Kaiser, U., \& Sofka, W. (2006). The pulse of liability of foreignness: dynamic legitimacy and experience effects in the German car market.

Kalyanasundaram, G. (2018). Why Do Startups Fail? A Case Study Based Empirical Analysis in Bangalore. Asian Journal of Innovation \& Policy, 7(1).

Karlsson, O., \& Rydqvist, F. (2017). Why are Swedish cleantech firms failing to internationalize? A qualitative study investigating the barriers, drivers and internationalization decisions of private Swedish cleantech firms.

Kozlova, A. (2014). Internationalization process of SMEs: motives and barriers. Case study of "Taste of North" (Master's thesis, Universitetet i Nordland).

Kritikos, A. S. (2014). Entrepreneurs and their impact on jobs and economic growth. IZA World of Labor. https://doi.org/10.15185/izawol.8

Mann, C., \& Sanyal, P. (2010). The financial structure of startup firms: The role of assets, information, and entrepreneur characteristics.

Mupemhi, S., Duve, R., \& Mupemhi, R. (2013). Factors Affecting the Internationalization of Manufacturing SMEs in Zimbabwe. ICBE-RF Research Report, (62/13).

OECD (2005). OECD SME and Entrepreneurship Outlook: 2005, OECD Paris.

OECD (2017). Enhancing the Contributions of SMEs in a Global and Digitalized Economy.

Ogunlana, F. (2018). The role of entrepreneurship as the driver of economic growth.

Onwuzuligbo, N., \& Hurmelinna-Laukkanen, P. (2017). Absorptive Capacity and Internationalization: A Case Study of Finnish Companies. International Business Management.

Patmore, F., \& Haddoud, M. (2015). The Drivers and Barriers Facing Small to Medium-sized Enterprises (SMEs) Entering the US Market. Journal of Research Studies in Business and Management, 1(1), 259-280.

Pietrasieński, P., \& Ślusarczyk, B. (2015). Internationalization of small and medium enterprises: empirical research review on barriers to entry into foreign markets. Polish Journal of Management Studies, 11(1), 113-123.

Prashantham, S., \& Yip, G. S. (2017). Engaging with startups in emerging markets.

Rauch, J. E. (2001). Business and Social Networks in International Trade. Journal of Economic Literature, 39, 1177-1203. https://doi.org/10.1257/jel.39.4.1177

Roy, A., Sekhar, C., \& Vyas, V. (2016). Barriers to internationalization: A study of small and medium enterprises in India. Journal of International Entrepreneurship, 14(4), 513-538. https://doi.org/10.1007/s10843-016-0187-7

Ruigrok, W., \& Wagner, H. (2003). Internationalization and performance: An organizational learning perspective. MIR: Management International Review, 63-83.

Saeedi, M. R. (2014). Fostering dynamic capabilities of SMEs.

Sekliuckiene, J. (2013). Lithuanian companies in emerging markets: internationalization motives and barriers. Economics and management, 18(1), 124-133. https://doi.org/10.5755/j01.em.18.1.3782 
Sieler, S. (2008). Determinants of the internationalization-performance relationship: An empirical examination of the influence of organizational and contextual variables.

Sinu, M. (2017). A Study on the Contribution of Start-Ups in the Economic Development of India. International Journal of Commerce, Business and Management (IJCBM), 6(2), 2319-2828.

Stouraitis, V., \& Kyritsis, M. (2016). Small and medium-sized enterprises' exporting: Home and host country motivators' effect on first and successive export venture decisions. Management: journal of contemporary management issues, 21(1), 97-115.

Techatassanasoontorn, A. A., Tapia, A. H., \& Powell, A. (2010). Learning processes in municipal broadband projects: An absorptive capacity perspective. Telecommunications Policy, 34(10), 572-595. https://doi.org/10.1016/j.telpol.2010.06.001

Toulova, M., Votoupalova, M., \& Kubickova, L. (2015). Barriers of SMEs internationalization and strategy for success in foreign markets. International Journal of Management Cases, 17(1), 4-19.

Vineburgh, J. H. (2010). A study of organizational trust and related variables among faculty members at HBCUs.

Wang, C., Walker, E., \& Redmond, J. (2007). Explaining the lack of strategic planning in SMEs: The importance of owner motivation.

Wu, A., \& Voss, H. (2015). When does absorptive capacity matter for international performance of firms? Evidence from China. International Business Review, 24(2), 344-351. https://doi.org/10.1016/j.ibusrev.2014.08.006

Yener, M., Doğruoğlu, B., \& Ergun, S. (2014). Challenges of Internationalization for SMEs and overcoming these Challenges: A case study from Turkey. Procedia-Social and Behavioral Sciences, 150, 2-11. https://doi.org/10.1016/j.sbspro.2014.09.002

Zhou, N., \& Guillen, M. F. (2016). Categorizing the Liability of Foreignness: Ownership, Location, and Internalization-Specific Dimensions. Global Strategy Journal, 6(4), 309-329. https://doi.org/10.1002/gsj.1140

\section{Copyrights}

Copyright for this article is retained by the author(s), with first publication rights granted to the journal.

This is an open-access article distributed under the terms and conditions of the Creative Commons Attribution license (http://creativecommons.org/licenses/by/4.0/). 